Article

\title{
Evaluation of Polyvinyl Alcohol/Cobalt Substituted Hydroxyapatite Nanocomposite as a Potential Wound Dressing for Diabetic Foot Ulcers
}

\author{
Wei-Chun Lin ${ }^{1}\left(\mathbb{D}\right.$ and Cheng-Ming Tang ${ }^{2,3, *}$ \\ 1 School of Dental Technology, College of Oral Medicine, Taipei Medical University, Taipei 110, Taiwan; \\ tukust94114wenny@gmail.com or Weichun1253@tmu.edu.tw \\ 2 Graduate Institute of Oral Sciences, Chung Shan Medical University, Taichung City 40201, Taiwan \\ 3 Department of Dentistry, Chung Shan Medical University Hospital, Taichung City 40201, Taiwan \\ * Correspondence: ranger@csmu.edu.tw; Tel.: +886-4-2471-8668 (ext. 55528); Fax: +886-4-2475-9065
}

Received: 21 September 2020; Accepted: 19 November 2020; Published: 22 November 2020

\begin{abstract}
Diabetic foot ulcers (DFUs) caused by diabetes are prone to serious and persistent infections. If not treated properly, it will cause tissue necrosis or septicemia due to peripheral blood vessel embolism. Therefore, it is an urgent challenge to accelerate wound healing and reduce the risk of bacterial infection in patients. In clinical practice, DFUs mostly use hydrogel dressing to cover the surface of the affected area as an auxiliary treatment. Polyvinyl alcohol (PVA) is a hydrophilic hydrogel polymer widely used in dressings, drug delivery, and medical applications. However, due to its weak bioactivity and antibacterial ability, leads to limited application. Filler adding is a useful way to enhance the biocompatibility of PVA. In our study, cobalt-substituted hydroxyapatite (CoHA) powder was prepared by the electrochemically-deposited method. PVA and PVA-CoHA nanocomposite were prepared by the solvent casting method. The bioactivity of the PVA and composite was evaluated by immersed in simulated body fluid for 7 days. In addition, L929 cells and E. coli were used to evaluate the cytotoxicity and antibacterial tests of PVA and PVA-CoHA nanocomposite. The results show that the addition of CoHA increases the mechanical properties and biological activity of PVA. Biocompatibility evaluation showed no significant cytotoxicity of PVA-CoHA composite. In addition, a small amount of cobalt ion was released to the culture medium from the nanocomposite in the cell culture period and enhanced cell growth. The addition of CoHA also confirmed that it could inhibit the growth of E. coli. PVA-CoHA composite may have potential applications in diabetic trauma healing and wound dressing.
\end{abstract}

Keywords: polyvinyl alcohol; cobalt-substituted hydroxyapatite; diabetic foot ulcers; hydrogels; antibacterial ability

\section{Introduction}

Diabetes is an endocrine disease caused by abnormal sugar and fat metabolism. It often causes other complications such as vascular disease, nephropathy, and diabetic foot ulcers (DFUs). Among them, DFUs are caused by poor long-term blood glucose control, which causes lower limb peripheral arterial disease and foot deformation [1]. When ulcers occur without proper treatment, it will cause tissue necrosis or amputation due to peripheral blood vessel embolism. In addition, bacteria can also spread through the blood circulation to cause septicemia and threaten the patient's life. Therefore, it is an urgent challenge to accelerate the speed of wound healing and reduce the risk of bacterial infection in patients. In clinical practice, dressing is often used to cover the surface of the affected area as one of the treatment methods for DFUs. The ideal wound dressing needs to have the following conditions: 
(1) can provide gas and liquid exchange to keep the wound properly moist [2,3]. (2) It has favorable biocompatibility and does not cause any immune response. (3) Protects wounds to reduce infection and (4) the dressing is easily removed and does not cause secondary trauma [4,5]. Based on the above conditions, hydrogel-like materials are widely used in wound dressing.

Polyvinyl alcohol (PVA) has excellent film forming properties and outstanding chemical stability, widely used in industry applications such as food packaging [6]. In addition, PVA has non-toxic and low protein adsorption properties, resulting in low cell adhesion compared to other hydrogel-like materials [7]. Therefore, it is developed in artificial cartilage substitutes, corneal implants [8], and drug delivery [9]. However, PVA is relatively limited in terms of its bioactivity compared to other polymers. On the other hand, nano-scale particles widely added into polymer to enhance its mechanical properties and thermal properties is a common modification procedure [10], while the effect of nano-scale particle additives is much more remarkable than that observed in conventional composites because of the high surface to volume ratio of the nano-scale particles. For example, the mechanical and thermal properties of PVA were outstanding, improved upon the addition of a small amount $(<5 \%)$ of bamboo charcoal nanoparticles $(107.4 \pm 9.8 \mathrm{~nm})$ [11].

Furthermore, hydroxyapatite (HA) is the main component of human bones and the calcium atom in the apatite inner structure can be substituted by divalent metal cations [12-14], altering the original properties of HA such as the lattice, crystallinity, and grain shape [15]. In addition, cobalt ion is a hypoxia-mimicking agent, which can activate the hypoxia inducible factor- 1 (HIF-1 $\alpha$ ) in bone marrow stromal stem cells and subsequently activate HIF-1 $\alpha$ target genes including erythropoietin and vascular endothelial growth factor (VEGF) [16-19]. This indicates that cobalt ions have the property of inducing angiogenesis. For problem wounds caused by diabetes, in addition to reducing wound infections, the supply of nutrients will also affect wound repair. Therefore, cobalt ions can be used to promote angiogenesis to help transport nutrients to the wound to help repair. Previous literature shows that synthesized cobalt-substituted hydroxyapatite (CoHA) $\left(\mathrm{Co}^{2+}\right.$ content $\left.12 \mathrm{wt} \%\right)$ can enhance osteogenesis in osteoporosis-induced alveolar defects after 24 weeks [20]. Our previous studies have confirmed that the release of cobalt ions through CoHA can promote bone cell growth, reduce free radicals, and enhance antibacterial effects [21,22]. This shows that CoHA is a potential choice for wound dressing additives.

According to the above, this study involves the preparation of PVA/CoHA composites membranes. The main objectives are to analyze the effect of CoHA on the properties of PVA and on improving the biocompatibility, anti-bacterial ability, and anti-inflammatory response of the membrane. We hypothesized that the addition of CoHA is significantly effective for the bioactivity and anti-inflammatory properties of the membranes. Finally, we assess whether the composite membrane could be used for the application of diabetic traumas.

\section{Results and Discussion}

\subsection{Characterization of $\mathrm{CoHA}$}

The surface morphology of CoHA shows a granular mixed structure (Figure 1A). It is evident that most of the nanoparticles are agglomerated. The surface elemental composition of CoHA was analyzed using energy dispersive X-ray spectroscopy (EDS) and cobalt elements were found (Figure 1B). The crystal structure of the powder was analyzed by XRD, diffraction peaks of HA crystals were observed at $26.01^{\circ}(002), 32.04^{\circ}(211), 39.68^{\circ}(310), 46.81^{\circ}$ (222), and $49.74^{\circ}$ (123) and diffraction peak of $\mathrm{Co}_{3} \mathrm{O}_{4}$ was observed at $18.8^{\circ}$ (111), which confirmed the presence of the CoHA structure (Figure 1C). The chemical compositions of $\mathrm{HA}$ and CoHA were obtained by FTIR. The absorption peaks at wavenumbers of $570.9 \mathrm{~cm}^{-1}$ represent $\mathrm{PO}_{4}^{3-}$. The peak at $3383 \mathrm{~cm}^{-1}$, representing $\mathrm{OH}^{-}$is observed in HA and CoHA, among which CoHA showed the largest peak shift (Figure 1D). This could be caused by the addition of $\mathrm{CoCl}_{2}$, which was combined with $\mathrm{OH}^{-}$to observe the peak shift [21]. 


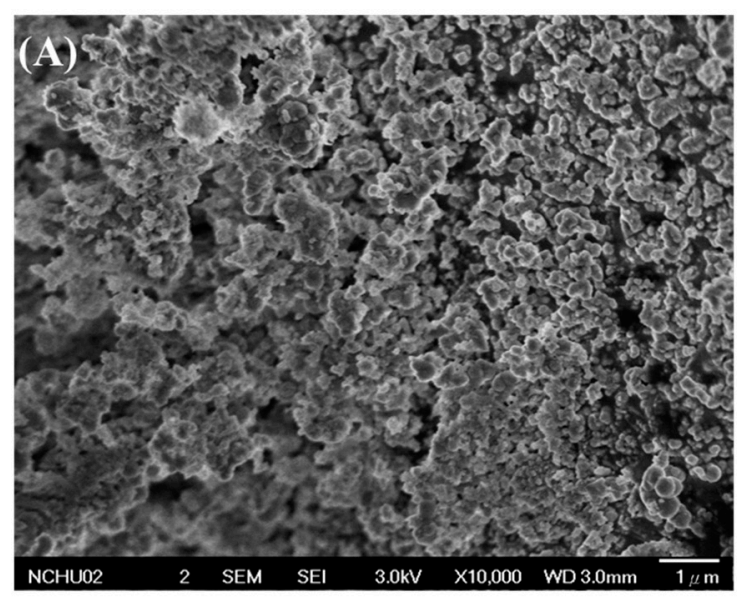

(B)
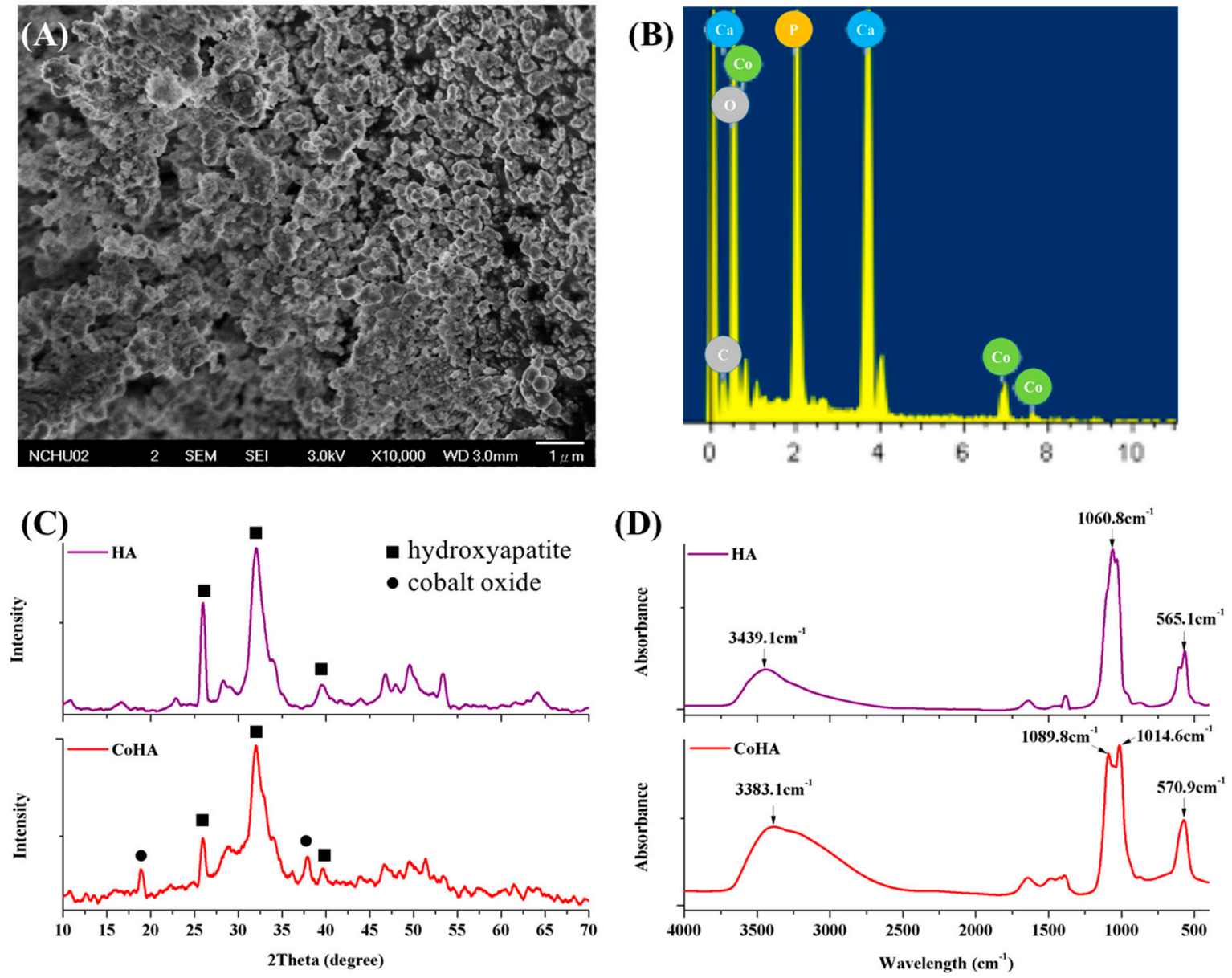

Figure 1. (A) Field emission scanning electron microscopy (FESEM) image of cobalt-substituted hydroxyapatite (CoHA) powder, (B) surface element analysis of CoHA by energy dispersive X-ray spectroscopy (EDS), (C) X-Ray diffraction (XRD) patterns of hydroxyapatite (HA) and CoHA, (D) IR spectra of HA and CoHA by FTIR.

\subsection{Characterization of PVA Nanocomposite}

Dried PVA and nanocomposite membranes had a smooth surface (data not shown). When the membranes were continuously immersed in distilled water at $37^{\circ} \mathrm{C}$ for $24 \mathrm{~h}$, the overall structure retains its integrity. However, swollen membranes were dehydrated and an interconnected porous structure on the surface was observed by FESEM (Figure 2A-C).

The crystal structure is one of the major factors that affect the mechanical properties of a material. The XRD patterns of the PVA and PVA/CoHA nanocomposites are presented in Figure 3A. The XRD pattern of the pure PVA membranes revealed strong crystalline reflections at around $2 \theta=19.88^{\circ}$ and a shoulder at $22.74^{\circ}$. The two peaks are characteristic of PVA, representing reflections from (101) and (200) from a monoclinic unit cell [23]. In the XRD profile of PVA/Co-HA nanocomposite membranes, no peak from Co-HA was observed in the XRD curves of the nanocomposites [11,24]. 

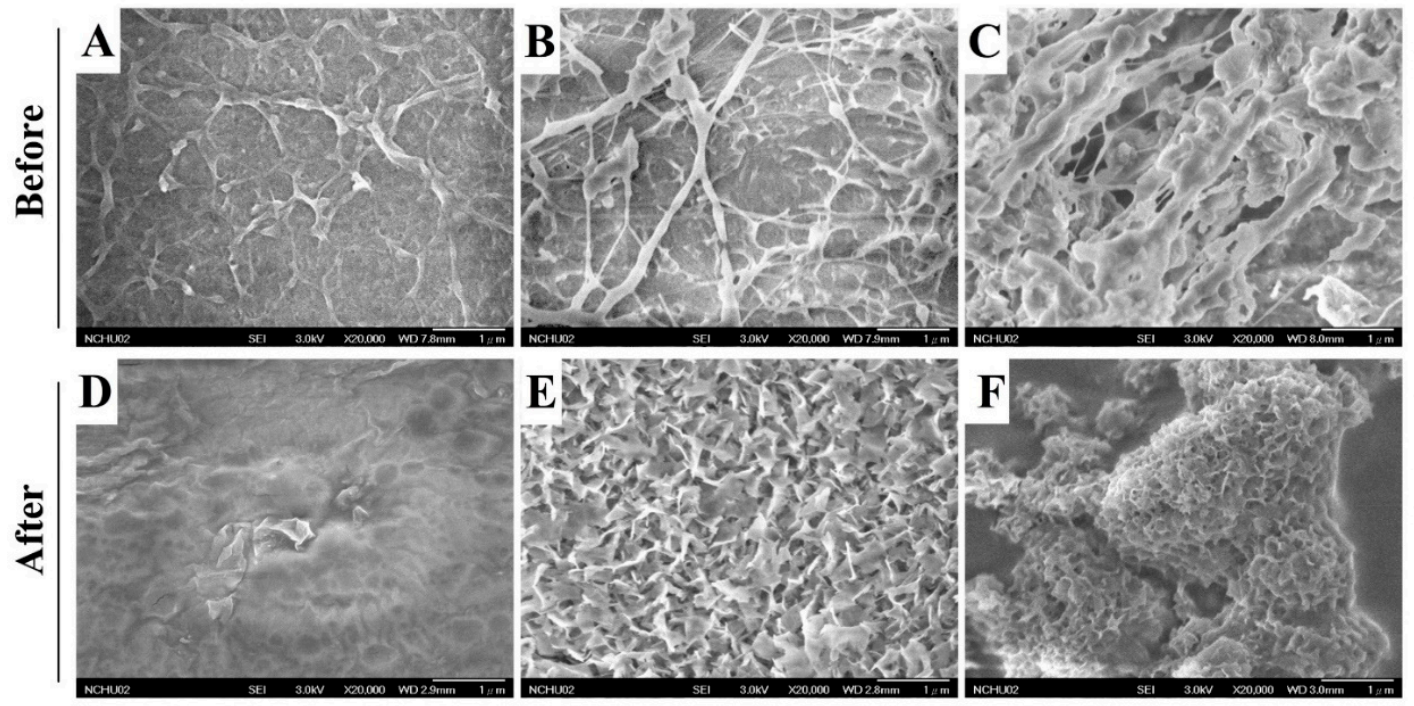

Figure 2. Surface morphology of (A,D) PVA, (B,E) PVA-HA nanocomposites, and (C,F) PVA-CoHA nanocomposites before and after immersion in SBF for 7 days.

ATR-FTIR analysis was conducted on the PVA and PVA nanocomposite membranes (Figure 3B,C). PVA absorption peaks appeared at $3255 \mathrm{~cm}^{-1}$ (stretching of OH), 2941, $2906 \mathrm{~cm}^{-1}$ (symmetric stretching of $\left.\mathrm{CH}_{2}\right), 1569 \mathrm{~cm}^{-1}\left(\mathrm{O}-\mathrm{H}\right.$ and $\mathrm{C}-\mathrm{H}$ bending), $1416 \mathrm{~cm}^{-1}$ (bending of $\mathrm{OH}$ and wagging of $\mathrm{CH}_{2}$ ), 1658 and $1330 \mathrm{~cm}^{-1}(\mathrm{C}=\mathrm{O}), 1142 \mathrm{~cm}^{-1}\left(\mathrm{CH}\right.$ wagging), $1086 \mathrm{~cm}^{-1}$ (stretching of $\mathrm{CO}$ and bending of $\mathrm{OH}$ from amorphous sequence of PVA), $920 \mathrm{~cm}^{-1}$ (CO symmetric stretching), and $837 \mathrm{~cm}^{-1}\left(\mathrm{CH}_{2}\right.$ rocking) [11,24-28]. The small bands found at $854 \mathrm{~cm}^{-1}$ were generated by the stretching vibrations of C-C bonds [23]. The crystallinity of PVA was obtained from the peak at $1143 \mathrm{~cm}^{-1}$ in the ATR-FTIR spectrum. The peak symmetric stretching mode of the C-C or C-O stretch of the chain is related to the intramolecular hydrogen bonding between two adjacent $\mathrm{OH}$ groups on the same side of the carbon plane [29]. The peak at $1143 \mathrm{~cm}^{-1}$ indicates that C-O is stretched from the crystalline sequence of PVA, while the peak at $1086 \mathrm{~cm}^{-1}$ indicates $\mathrm{C}-\mathrm{O}$ stretching from the amorphous sequence of PVA [30]. Therefore, the ratio of the two peaks reflects the crystallinity of PVA. The position strengths through $1143 \mathrm{~cm}^{-1} / 1086 \mathrm{~cm}^{-1}$ is calculated as surface crystallinity of PVA $(\%)=$ [Absorbance at $1143 \mathrm{~cm}^{-1} /\left(\right.$ Absorbance at $1143 \mathrm{~cm}^{-1}+$ Absorbance at $\left.\left.1086 \mathrm{~cm}^{-1}\right)\right] \times 100 \%$. The results show that the addition of pure HA and CoHA slightly increases the crystallinity on the surface of the membranes (Table 1), but there is no significant difference.

Table 1. The relative intensities of $1143 \mathrm{~cm}^{-1}$ and $1086 \mathrm{~cm}^{-1}$ peak in ATR-FTIR spectra of PVA and PVA/CoHA nanocomposites.

\begin{tabular}{ccc}
\hline Sample & $\begin{array}{c}\text { Absorbance } \\
\left.\mathbf{( 1 1 4 3} \mathbf{~ c m}^{\mathbf{- 1}} \mathbf{1 0 8 6} \mathbf{~ m}^{-\mathbf{1}}\right)\end{array}$ & Surface Crystallinity (\%) \\
\hline PVA & 0.524 & $34.4 \%$ \\
PVA-HA & 0.544 & $35.2 \%$ \\
PVA-CoHA & 0.550 & $35.5 \%$ \\
\hline
\end{tabular}

Tensile testing showed that the addition of CoHA significantly increased the tensile strength and ductility of PVA (Figure 3D). This result is similar to the literature, adding a small number of nanoparticles can improve the mechanical properties of the polymer [11]. In addition, the $\mathrm{OH}$ group on the molecular chain of CoHA and PVA generates a hydrogen bond to restrict the movement of the molecular chain which is called the crystalline region. However, the unaffected molecular chains can move freely and are called amorphous regions. As shown in Figure 3E, the crystalline region acts to enhance mechanical strength, while the non-crystalline region imparts ductility to the film. 

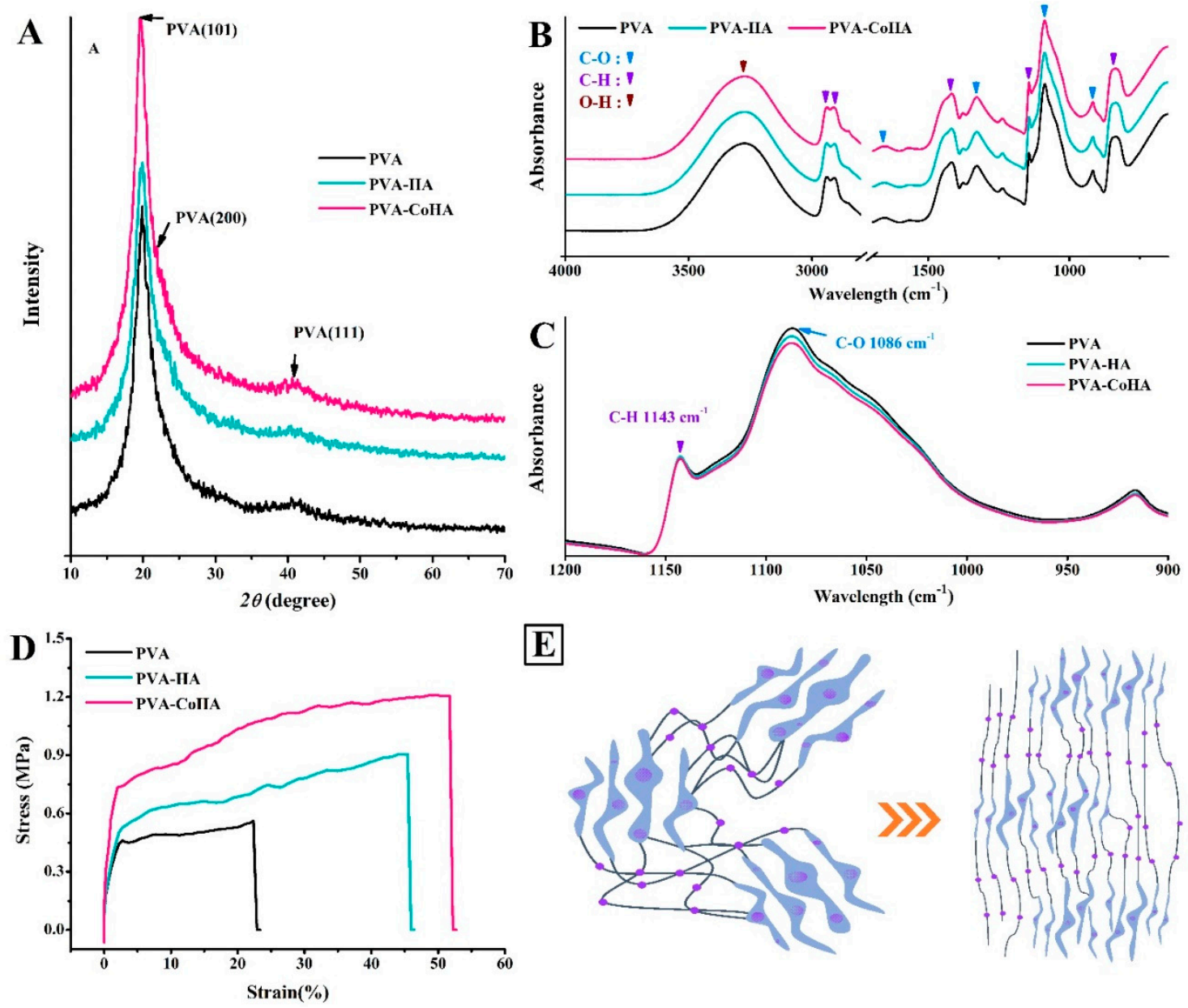

$\mathbf{E}$

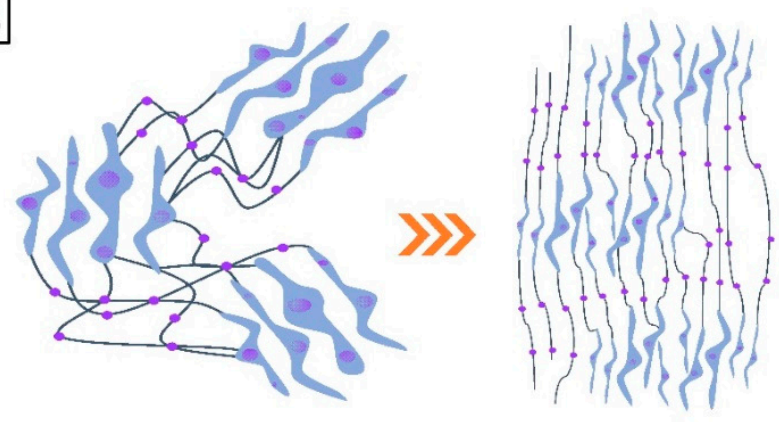

Figure 3. (A) XRD patterns, (B,C) ATR-FTIR spectra, and (D) stress-strain curve of PVA and PVA-CoHA nanocomposites. (E) Structure model for extended PVA-CoHA.

\subsection{Thermal Properties}

Thermal properties of the PVA and nanocomposites were assessed using thermo-gravimetric analyzer (TGA) and differential scanning calorimetry (DSC) data and are summarized in Table 2. Treating PVA at $100{ }^{\circ} \mathrm{C}$ completely removed any moisture present, [24] and heating it at $247-362{ }^{\circ} \mathrm{C}$ caused rapid decomposition (Figure $4 \mathrm{~A}, \mathrm{~B}$ ). The composite film changes at $380^{\circ} \mathrm{C}$. The addition of $\mathrm{CoHA}$ was found to slow down the weight loss of PVA. From the SEM (Figure 2A-C) speculation, this phenomenon can be explained by the fact that PVA uniformly coats CoHA particles and makes the structure denser. It also explains that PVA-CoHA has a higher crystallinity of PVA internally. PVA-CoHA heated to $400{ }^{\circ} \mathrm{C}$ led to $20.75 \%$ residual material, significantly higher than the case of pure PVA (13.32\% residual, Table 2). The ash content of PVA-CoHA at the temperature end point $\left(600{ }^{\circ} \mathrm{C}\right)$ is still higher than that of pure PVA $\left(3.08 \%\right.$ at $\left.400{ }^{\circ} \mathrm{C}\right)$, denoting that CoHA content also increases the thermal properties of PVA. The results of Xc are also listed in Table 3. DSC results show that the addition of CoHA can significantly increase the crystallization of PVA, which is consistent with the XRD results where the typical PVA peak (101) in PVA-CoHA is the highest. 

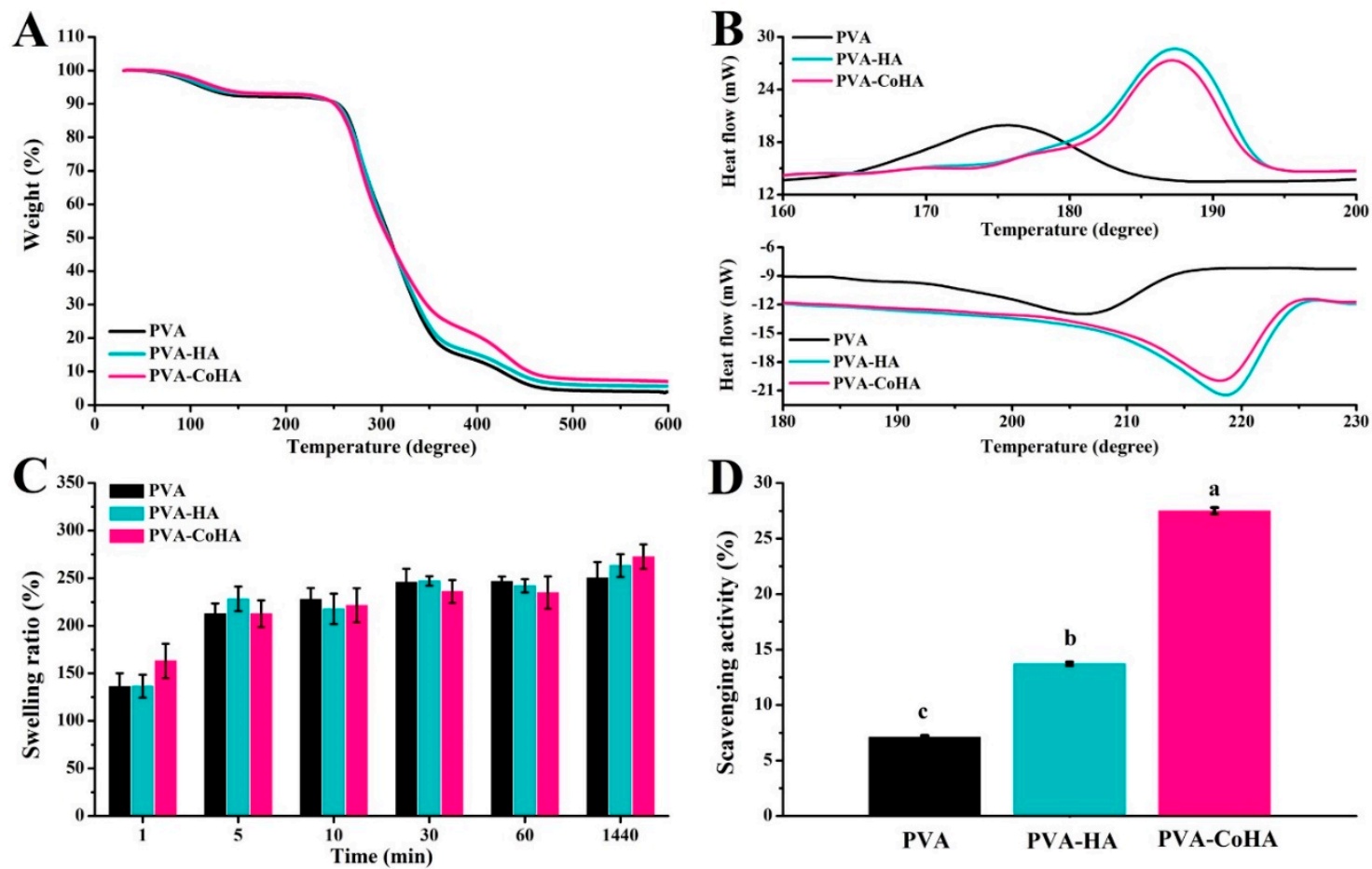

Figure 4. (A) TGA patterns, (B) DSC patterns, (C) swelling behaviors curve, and (D) free radical scavenging ability of PVA and PVA-CoHA nanocomposites. Means with different letters $(\mathrm{a}-\mathrm{c})$ were significantly different $(p<0.05$, mean $\pm \mathrm{SD}, n=4)$.

Table 2. Thermal properties of PVA and PVA/CoHA nanocomposites.

\begin{tabular}{cccccccc}
\hline Sample & $\begin{array}{c}\mathbf{T}_{\text {onset }} \\
\left({ }^{\circ} \mathbf{C}\right)\end{array}$ & $\begin{array}{c}\mathbf{T}_{\mathbf{p}} \\
\left({ }^{\circ} \mathbf{C}\right)\end{array}$ & $\begin{array}{c}\text { Ash } \\
\mathbf{( \% )}\end{array}$ & $\begin{array}{c}\mathbf{T}_{\mathbf{c}} \\
\left({ }^{\circ} \mathbf{C}\right)\end{array}$ & $\begin{array}{c}\mathbf{T}_{\mathbf{m}} \\
\left({ }^{\circ} \mathbf{C}\right)\end{array}$ & $\begin{array}{c}\triangle \mathbf{H}_{\mathbf{m}} \\
(\mathbf{J} / \mathbf{g})\end{array}$ & $\mathbf{X}_{\mathbf{c}}$ \\
\hline PVA & 113.0 & 308.3 & 0 & 175.5 & 206.2 & 40.7 & 27.1 \\
PVA-HA & 118.0 & 307.2 & 1.7 & 187.4 & 218.5 & 53.6 & 36.1 \\
PVA-CoHA & 127.8 & 306.2 & 3.1 & 187.2 & 218.0 & 61.6 & 41.5 \\
\hline
\end{tabular}

$\mathrm{T}_{\text {onset: }}$ onset temperature of pyrolysis, obtained from TGA curves at $95 \%$ weight; $\mathrm{T}_{\mathrm{p}}$ : peak pyrolytic temperature, obtained from TGA curves at $50 \%$ weight. Crystallization temperature $\left(\mathrm{T}_{\mathrm{c}}\right)$, melting temperature $\left(\mathrm{T}_{\mathrm{m}}\right)$ and heat of fusion of PVA $\left(\Delta \mathrm{H}_{\mathrm{m}}\right)$, obtained from DSC.

\subsection{Swelling Behavior}

Swelling property of wound dressing will affect drug release properties and interactions with tissue fluid on wound position. Therefore, swelling behavior is one of the important indicators for evaluating dressings. PVA and PVA-CoHA membranes were immersed in PBS as a model for human contact $(\mathrm{pH}=7.42)$ at $37^{\circ} \mathrm{C}$, and the swelling behavior was calculated at different immersion times (Figure 4C). The results showed that PVA and PVA-CoHA nanocomposites membranes have rapid and good swelling properties (Figure 4C), where soaking in PBS for one minute leads to $150 \%$ expansion. After $24 \mathrm{~h}$ soaking in PBS, the membrane reached $260 \%$ expansion and an equilibrium state, and statistical analysis indicated no significant differences among the tested sample groups. Therefore, the addition of CoHA does not affect the swelling behavior of PVA and can ensure that the membrane maintains a good water absorption effect.

\subsection{Free Radical Scavenging Ability}

Anti-inflammatory effects of wound dressings have attracted more attention. Biological defense and the differentiation process will produce free radicals. However, excessive free radicals may cause excessive oxidation. Antioxidants can capture excessive harmful free radicals to maintain the normal 
growth of organisms. Therefore, they play an important role in this balance. Figure $4 \mathrm{D}$ shows the free radical scavenging ability of the PVA-Co-HA composite membrane. The capture capacity of PVA-CoHA was significantly higher than that of pure PVA or PVA-HA $(p<0.05)$. It is mainly the exposed CoHA on the surface that allows PVA-CoHA to combine with more free radicals. Therefore, it indirectly indicates that PVA-CoHA can reduce the anti-inflammatory effect of cells and reduce the inflammatory response of wounds.

\subsection{Hydrophilicity Test}

The hydrophilicity and hydrophobicity of the material surface is one of the important indicators of biomedical materials [31]. Use contact angle measurement to evaluate the hydrophilicity and hydrophobicity of the material surface to observe the effect of the material surface on cell adhesion. It is reported in the literature that increasing the hydrophilicity of the material can improve its biological activity and contribute to cell adhesion [32]. In order to evaluate the surface contact angle of the PVA membranes after contact with the skin. In this study, PBS was used as the test solution. The results show that both PVA and PVA-CoHA nanocomposites membranes are hydrophilic materials (Figure 5). In addition, the time that the solution stays on the surface is negatively correlated with the contact angle. This is similar to the result of swelling. The PVA membranes start to absorb the liquid on the surface after $1 \mathrm{~min}$ and reduced the contact angle. However, the surface of PVA-HA and PVA-CoHA is relatively hydrophilic due to the combination of the structural solution with $\mathrm{OH}$ on the surface and water molecules. Especially the SEM image can find that the exposure of CoHA in PVA-CoHA is more obvious, which leads to a significantly smaller contact angle than other groups $(p<0.05)$. The above addition of HA and CoHA can effectively improve the hydrophilicity of the PVA surface.

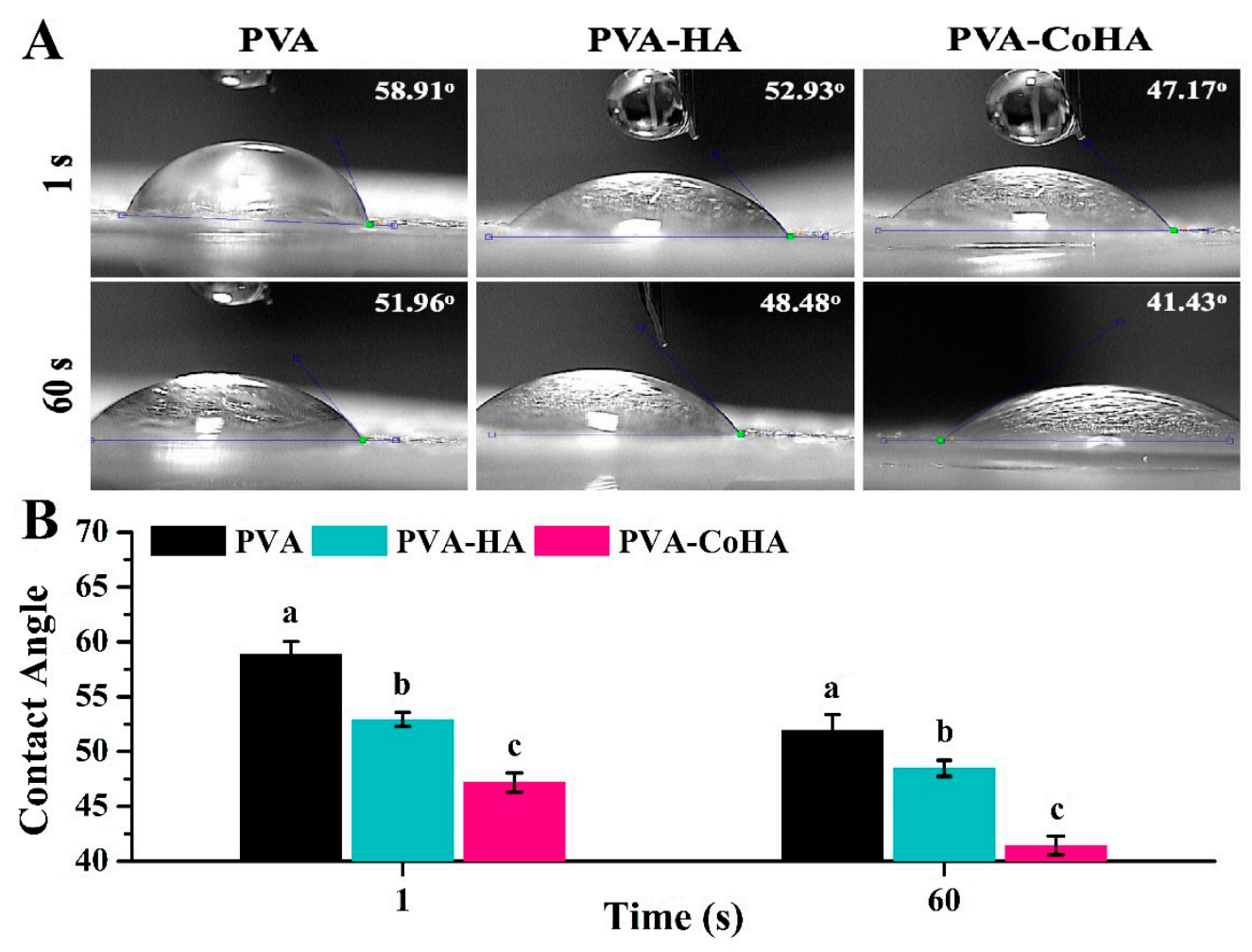

Figure 5. The surface wettability of PVA and PVA nanocomposites. (A) Image of surface contact angle. (B) Quantitative analysis of the contact angle was performed. Means with different letters (a-c) were significantly different $(p<0.05$, mean $\pm \mathrm{SD}, n=5)$. 


\subsection{Bioactivity}

Many studies use surface mineralization results to evaluate the bioactivity of materials. Surface mineralization results are given in Figure 2D-F for PVA and PVA-CoHA nanocomposites membranes placed in $37^{\circ} \mathrm{C}$ SBF solution for 7 days. The pure PVA membrane surface did not produce HA at any exposure time, while PVA-HA and PVA-CoHA produced HA, especially after 7 days of SBF exposure.

Based on EDS data, the $\mathrm{Ca} / p$ ratios of different sample types were 1.29 (PVA-HA) and 1.39 (PVA-CoHA). The apatite crystal faces also differ between samples, where the PVA-HA crystalline morphology is a sheet of flat HA. PVA-CoHA feature lamellae divided into regions rather than a flat surface, which may be due to the impact of cobalt ion remineralization during crystallization. Notably, there were cobalt ions before immersion in the CoHA samples, and after 7 days of SBF immersion these ions disappeared due to apatite deposition (Table 3). This indicates that the membrane surface undergoes new HA deposition, covering the cobalt ions. XRD data show that the diffraction peaks of pure PVA do not produce new peaks after SBF soaking, indicating that the membrane does not undergo mineralization (Figure 6A). HA and CoHA were added to membranes, creating a new diffraction peak at $26^{\circ}$ and $32^{\circ}$. The diffraction peaks for HA are (002) and (112), respectively [11]. The ATR-IR spectrum of the PVA film mineralization is shown in Figure 6B. In addition to the pure PVA membrane, the peak at $1027 \mathrm{~cm}^{-1}$ is generated from HA with a phosphate group [33]. As the apatite surface is exposed, the calcium and phosphorus ions in the SBF solution deposited on the membrane surface. These results confirm that the addition of HA and CoHA can significantly enhance the bioactivity effect of PVA membranes.
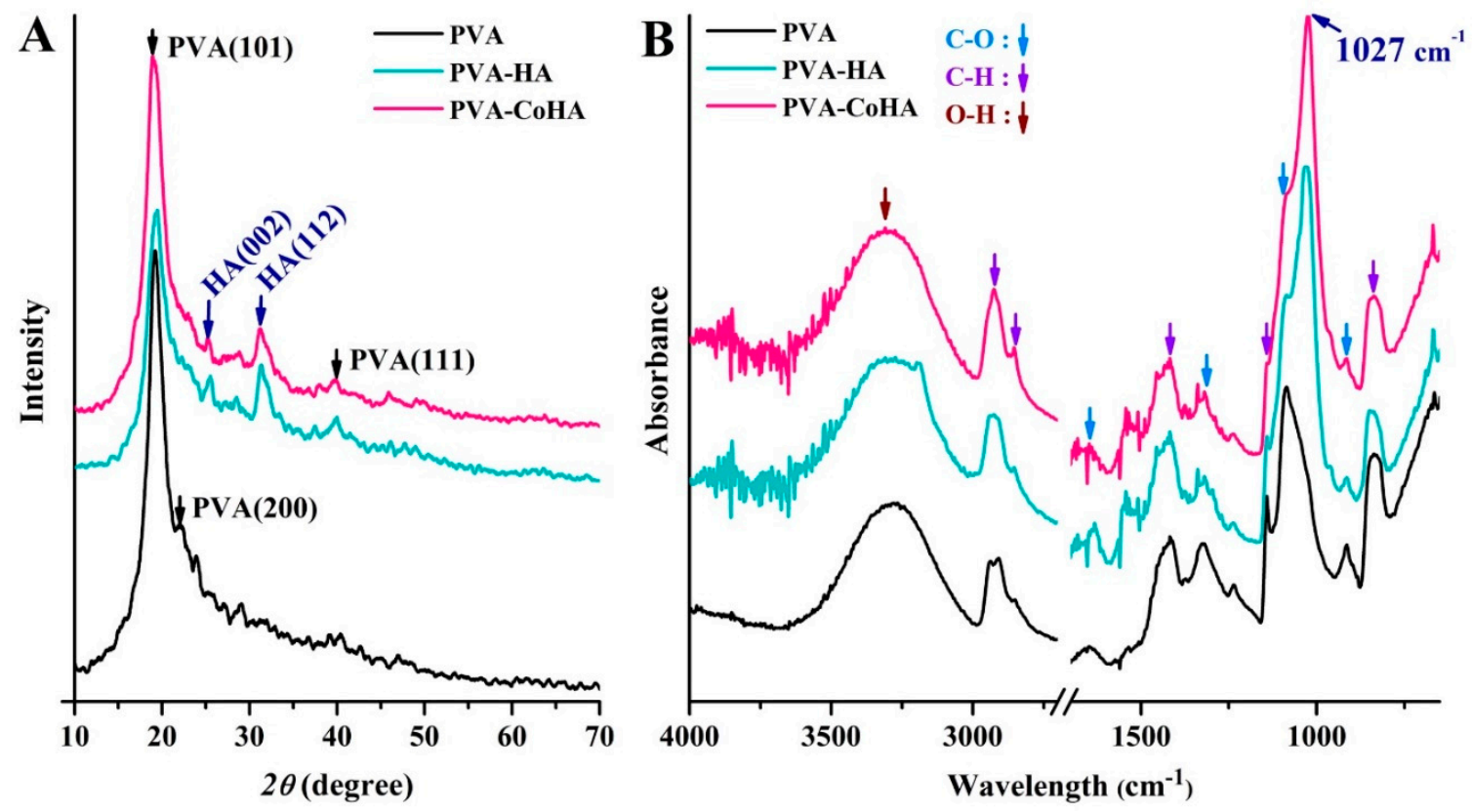

Figure 6. (A) XRD patterns and (B) ATR-FTIR spectra of PVA and PVA-CoHA nanocomposites after immersion in SBF for 7 days.

Table 3. Calcium to phosphate $(\mathrm{Ca} / \mathrm{P})$ ratio of PVA and PVA nanocomposites surface.

\begin{tabular}{cclcc}
\hline Group & Ratio & PVA & PVA-HA & PVA-CoHA \\
\hline \multirow{2}{*}{ Before Immersion } & $\mathrm{Ca} / \mathrm{P}$ & N.D. & 1.02 & 0.86 \\
& $\mathrm{Ca}+\mathrm{Co} / \mathrm{P}$ & N.D. & 1.02 & 0.94 \\
\hline Immersed in SBF & $\mathrm{Ca} / \mathrm{P}$ & N.D. & 1.29 & 1.40 \\
for 7 Days & $\mathrm{Ca}+\mathrm{Co} / \mathrm{P}$ & N.D. & 1.29 & 1.40 \\
\hline
\end{tabular}




\subsection{Biocompatibility}

Membrane biocompatibility was evaluated using L929 fibroblasts cultured with PVA and PVA-CoHA nanocomposites in vitro. PVA is a hydrophilic material and has excellent swelling effects, so it will reduce the adhesion ability of cells after swelling, making it difficult to evaluate the cytotoxicity of surface cells.

This part of the study is divided into two parts: the membrane surfaces directly in contact with cultured cells, and the extraction of membrane fluid to test the cytotoxicity. As shown in Figure 7A, tissue culture plate (TCP) is significantly higher than the other groups, indicating that cells in the membrane have less desirable surface adhesion. After $24 \mathrm{~h}$, cell attachment for PVA was significantly higher than for the other groups. Seventy-two hours later, the number of PVA-HA and PVA-CoHA cells was not significantly different than for pure PVA. Affixed experiments show that PVA membrane surface cells have poor attachment. For wound dressings however, this phenomenon means that the tissue surrounding the wound is less likely to stick with the dressing and will cause secondary damage.

As to whether the reduction of cells is caused by the release of cobalt ions, we do not know, so the second part uses the membrane material extraction solution for cytotoxicity testing according to the method of ISO 10993-12. The results of the cell culture with the membrane extraction solution are shown in Figure 7B. After the initial $24 \mathrm{~h}$ exposure, the results of PVA-HA were significantly higher than for all other groups, and the CoHA groups grow slowly. After $72 \mathrm{~h}$, PVA-CoHA was significantly higher than TCP and pure PVA, but did not differ significantly from the HA groups. The extraction results confirm that the PVA composite membrane has no obvious cytotoxicity. Notably, the release of cobalt ions slows cell growth when cells are initially attached, but it aids cell growth in the latter part of cell proliferation.
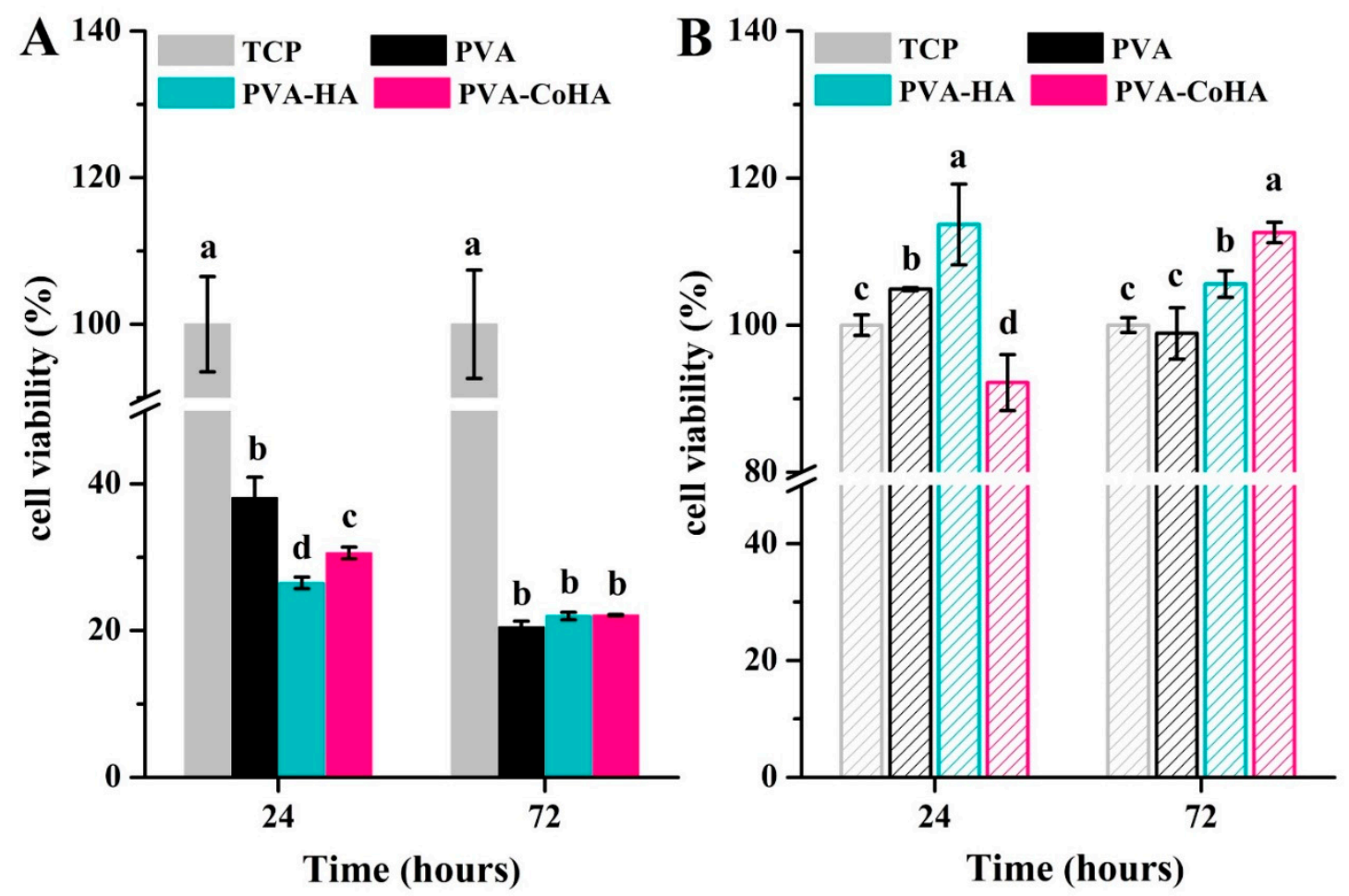

Figure 7. Biocompatibility of the PVA and PVA-CoHA nanocomposite. (A) Cells are grown on the surface. (B) The cells are cultured using extraction solutions. Means with different letters (a-d) were significantly different $(p<0.01$, mean $\pm \mathrm{SD}, n=4)$. 


\subsection{Antibacterial Ability}

Due to slower recovery in diabetic traumas, wounds are vulnerable to invasion by surrounding bacteria. Therefore, current wound dressings still add antibacterial agents or nanoparticles to achieve antibacterial effects. Through this method, the wound is protected from infection by bacteria on the periphery. In this study, E. coli was used to evaluate the antibacterial ability of the membrane. The sample surface of each E. coli test was added to a new medium, and $100 \lambda$ bacteria was extracted to a petri dish-coated plate for $17 \mathrm{~h}$ growth (Figure $8 \mathrm{~A}-\mathrm{C}$ ). The number of colonies on a labelled petri dish $(n=3)$ and single factor analysis of variance (ANOVA) were used to assess the statistical significance of the results in Figure 8. That PVA-CoHA group eminently reduced the bacteria viability almost by 87.4\% compared to the PVA group (control). The results show that PVA-CoHA has a good antibacterial effect (Figure 8D). Previous studies have also shown that CoHA particles can inhibit the growth of bacteria through the release of cobalt ions [34]. In this study, the CoHA content in PVA-CoHA was very small. Therefore, achieving $100 \%$ antibacterial is challenging. Perhaps in the future, the effect of antibacterial ability can be improved by increasing the content of CoHA. Moreover, literature indicates that using $\mathrm{Co}_{3} \mathrm{O}_{4}$ nanoparticles for $E$. coli treatment is effective, with potential for use as antimicrobial agents [35]. This is similar to the results of this experiment and also confirms that the antibacterial effect comes from the addition of cobalt ions. Therefore, PVA added CoHA has the opportunity to inhibit the bacteria around the wound and prevent wound infection.
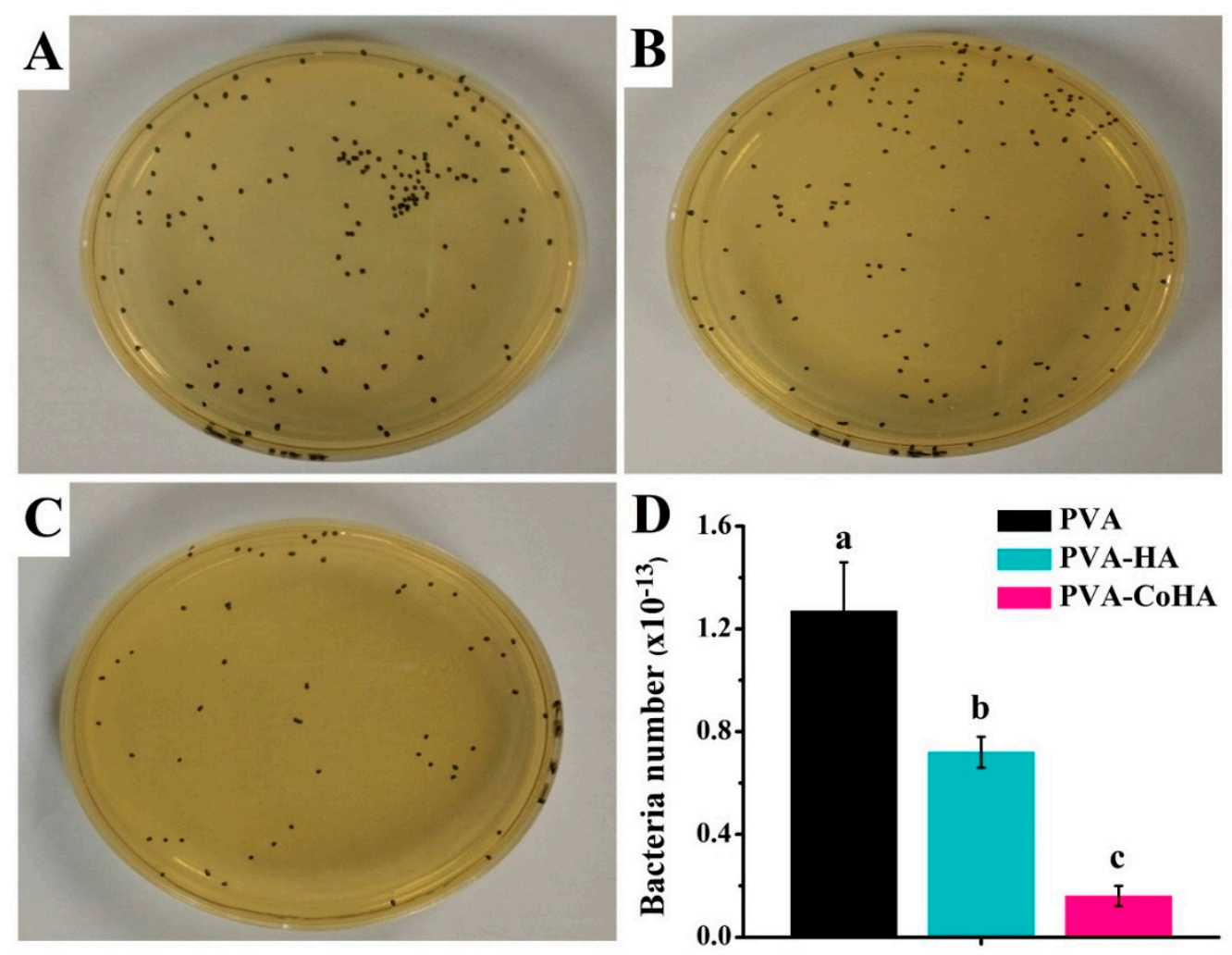

Figure 8. Evaluation of the antibacterial activity of (A) PVA, (B) PVA-HA and (C) PVA-CoHA nanocomposites against E. coli. (D) Bacteria adhesion on PVA and PVA-CoHA nanocomposites. Means with different letters $(\mathrm{a}-\mathrm{c})$ were significantly different $(p<0.01$, mean $\pm \mathrm{SD}, n=4)$.

\section{Materials and Methods}

\subsection{Synthesis of $\mathrm{CoHA}$}

The CoHA powder was prepared by electrochemical deposition [21]. The electrolyte solution was formulated with $42 \mathrm{mM}$ calcium nitrate (Shimakyu's pure chemical, Osaka, Japan), $25 \mathrm{mM}$ ammonium 
dihydrogen phosphate (Showa, Tokyo, Japan), and $7.98 \mathrm{mM}$ cobalt chloride (Shimada chemical works, Tokyo, Japan) in de-ionized water. The titanium sheet was a cathode, the stainless-steel sheet was an anode. The electrodeposition procedure was carried out with a direct current power supply (GR-50H10, GICEK, Taipei, Taiwan) and at constant potential by $5.5 \mathrm{~V}$ at $328 \mathrm{~K}$ for $20 \mathrm{~min}$. After the reaction was completed, rinsed with deionized water and dried, the powder was removed from the surface and collected.

\subsection{Preparation of PVA and Nanocomposite}

The PVA used in this study was obtained from Sigma-Aldrich (St. Louis, MO, USA). The PVA has a molecular weight of 70,000-110,000 g/mole and hydrolysis grade of $98.5 \%$. The homogeneous PVA solution was prepared by adding $1.485 \mathrm{~g}$ of PVA in $10 \mathrm{~mL}$ of distilled water and stirring at $85^{\circ} \mathrm{C}$ for $30 \mathrm{~min}$. Then, $15 \mathrm{mg}$ of CoHA (or HA) powder was then added to the PVA solution and stirred for $24 \mathrm{~h}$ at room temperature. The above solution was poured into a polytetrafluroethylene mold $(90 \mathrm{~mm}$ in diameter) and placed in a fume hood until the solvent evaporated.

\subsection{Characterization of PVA and Nanocomposite}

The surface morphology of the PVA and PVA/CoHA nanocomposite was examined by field-emission scanning electron microscopy (FESEM) (JSM-6700F, JEOL, Tokyo, Japan). Phase indication in samples was confirmed by X-ray diffraction (XRD) (Miniflex II, Rigaku corporation, Tokyo, Japan), operating at $30 \mathrm{kV}$ with $\mathrm{Cu}-\mathrm{K} \alpha$ radiation within the scanning range of $10-70^{\circ}(2 \theta)$ and a scanning speed of $4^{\circ} / \mathrm{min}$. Infrared spectra of PVA and composite were recorded using a Fourier transform infrared (FTIR) system (FTIR-8000, Shimadzu, Tokyo, Japan) in the spectral range of $650-4000 \mathrm{~cm}^{-1}$ with a spectral resolution of $2 \mathrm{~cm}^{-1}$, using the attenuated total reflection (ATR) mode. Tensile tests of the PVA and PVA nanocomposites were carried out with universal testing machine (GF-AI-7000M, GO TECH, Taichung, Taiwan) instruments by applying a $10 \mathrm{~N}$ load cell at a crosshead speed of $10 \mathrm{~mm} / \mathrm{min}$. All samples were cut with a dumbbell-shaped mold $40 \mathrm{~mm}$ long and $20 \mathrm{~mm}$ wide. The average value of tensile properties was obtained from the results of 3 tests.

\subsection{Thermal Properties}

The thermos-gravimetric analysis (TGA) was carried out on the PVA and PVA nanocomposites using a Q500, TA instrument analyzer (New castle, DE, USA). The samples were heated from $30-600^{\circ} \mathrm{C}$ at a heating rate of $10{ }^{\circ} \mathrm{C} / \mathrm{min}$ under nitrogen, with a nitrogen flow rate of $30 \mathrm{~mL} / \mathrm{min}$. The differential scanning calorimetry (DSC) of samples were measured under $\mathrm{N}_{2}$ atmosphere with a Q10, TA instrument thermal analyzer (New castle, DE, USA). Samples for DSC measurements were prepared from several circular pieces cut from the polymer film to a mass of about $10 \mathrm{mg}$. The temperature range studied was $30-400{ }^{\circ} \mathrm{C}$. The heating $/$ cooling rate was $10^{\circ} \mathrm{C} / \mathrm{min}$. The degree of inside crystallinity $(X \mathrm{c})$ of the PVA membrane was calculated by the following well Equation (1) [11]:

$$
X_{C}=\frac{\Delta H m}{W \times \Delta H_{0}} \times 100
$$

where $\Delta H_{0}$ is the apparent enthalpy of crystallization, $\Delta H_{\mathrm{m}}$ is the extrapolated value of the enthalpy corresponding to the melting of a $100 \%$ crystalline sample $(138.6 \mathrm{~J} / \mathrm{g})$.

\subsection{Swelling Behavior}

The swelling was measured by immersing the samples in phosphate buffer saline (PBS). All samples were dried in an incubator which was maintained at $37^{\circ} \mathrm{C}$ until no change of mass was observed. After, the excessive water on the surface was removed with filter paper. The fully swollen samples were again weighed. The swelling ratio can be calculated as a function of time as swelling 
ratio $(\%)=\left[\left(\mathrm{W}_{\mathrm{w}}-\mathrm{W}_{\mathrm{d}}\right) / \mathrm{W}_{\mathrm{d}}\right] \times 100 \%$, where $\mathrm{W}_{\mathrm{d}}$ is the weight in the dry state of a sample and $\mathrm{W}_{\mathrm{w}}$ is the weight in the swollen state of the sample.

\subsection{Free Radical Scavenging Ability}

The 2,2-diphenyl-1-picrylhydrazyl (DPPH) was used to evaluate the free radical scavenging ability of PVA and PVA nanocomposites [11]. A control of distilled water (1 mL) or $1 \mathrm{~mL}$ of deionized water containing PVA and PVA nanocomposites $\left(30 \times 10 \mathrm{~mm}^{2}\right)$ was added to $3 \mathrm{~mL}$ of DPPH in methanol and left to stand for $90 \mathrm{~min}$. Absorbance of the reaction mixture was then measured at $515 \mathrm{~nm}$ with an ultraviolet-visible spectrophotometer (Helios Zeta, Thermo, Waltham, MA, USA). Free radical scavenging ability effect is determined by the following equation: scavenging ratio $(\%)=$ [1 - (absorbance of test sample/absorbance of control) $] \times 100 \%$.

\subsection{Hydrophilicity Test}

The hydrophilicity and hydrophobicity were evaluated through the contact angle test of the material surface. The surface hydrophilicity of the PVA and PVA nanocomposites was evaluated by a contact angle meter (CA-D, Kyowa interface science, Tokyo, Japan). The static contact angle was determined at $25{ }^{\circ} \mathrm{C}$ by employing drops of PBS. The quantitative titration of the water drop used was $4 \mu \mathrm{L}$ and the time was 1 and $60 \mathrm{~s}$. After that, the image was analyzed using the Drop-analysis software attached to Image $\mathrm{J}$ for contact angle analysis.

\subsection{Bioactivity}

Simulated body fluid (SBF) was prepared with ionic concentrations nearly equal to those of human blood plasma $\left(\mathrm{K}^{+}\right.$5.0, $\mathrm{Na}^{+}$142.0, $\mathrm{Ca}^{2+}$ 2.5, $\mathrm{Mg}^{2+} 1.5, \mathrm{Cl}^{-}$103.0, $\mathrm{HCO}_{3}{ }^{-} 4.2, \mathrm{HPO}_{4}{ }^{2-}$ 1.0, and $\mathrm{SO}_{4}{ }^{2-}$ $0.5 \mathrm{mM}$; pH 7.42). Samples were pre-cut into square shapes $(10 \mathrm{~mm} \times 20 \mathrm{~mm})$ and then immersed in $10 \mathrm{~mL}$ of SBF solution in a plastic container, which was tightly closed and kept at $37^{\circ} \mathrm{C}$. The samples were removed after seven days, rinsed with distilled water and lyophilized by a freeze-drying device (FDU-1200, EYELA, Tokyo, Japan) for $24 \mathrm{~h}$ [11].

\subsection{Biocompatibility}

To evaluate the biocompatibility, $100 \mu \mathrm{L}$ polymer solution was coated on a circular glass substrate (15 mm in diameter) and dried. Mouse-derived fibroblasts cell line (L929) was maintained in Dulbecco's modified eagle medium (DMEM) and supplemented with $10 \%$ fetal bovine serum (FBS) at $37^{\circ} \mathrm{C}$ in a $5 \%$ $\mathrm{CO}_{2}$ incubator. Before cell seeding, all samples were sterilized with UV radiation for $1 \mathrm{~h}$. The sterilized samples were placed into 24-well culture plates and seeded with a cell suspension with a cell density of $5 \times 10^{4}$ cells $/ \mathrm{mL}$, followed by culturing for 24 and $72 \mathrm{~h}$ at $37^{\circ} \mathrm{C}$ in $5 \% \mathrm{CO}_{2}$ incubator. After incubation, samples were rinsed with PBS, followed by incubation in a culture medium containing $1 \mathrm{~mL}$ MTT reagent for $4 \mathrm{~h}$. After removal of the medium, $0.5 \mathrm{~mL}$ of dimethyl sulfoxide (DMSO) was added to the wells. The $0.1 \mathrm{~mL}$ from each sample solution was transferred to 96-well plates and the optical density (O.D.) was measured at 563-650 nm. In addition, the membrane extraction in this study followed the ISO 10993-12 standard. PVA and PVA nanocomposite membranes were cut into square shapes $\left(3 \mathrm{~cm}^{2}\right)$ and subjected to sterilization by UV light for $30 \mathrm{~min}$. Then, they were immersed in $75 \%$ ethanol solution and followed by PBS replacement. The membrane was immersed in DMEM at $37^{\circ} \mathrm{C}$ for $24 \mathrm{~h}$. After, immersion in $1 \mathrm{~mL}$ DMEM with $10 \% \mathrm{FBS}$ at $37^{\circ} \mathrm{C}$ in a $5 \% \mathrm{CO}_{2}$ incubator for $24 \mathrm{~h}$. The extraction solution acquired for each membrane was harvested and used in MTT to determine the cytotoxicity.

\subsection{Antibacterial Ability}

PVA and PVA nanocomposite were investigated against E. coli as a model Gram-negative bacteria by the colony plate count method in order to quantify the bacterial effect of our system. The $E$. coli were prepared from fresh brain heart infusion (BHI, Becton Drive, Franklin Lakes, NJ, USA) and incubated 
at $37^{\circ} \mathrm{C}$ for $24 \mathrm{~h}$. The BHI containing E. coli was dilute to $10^{11}$ times the original concentration. Disc shapes ( $5.5 \mathrm{~mm}$ in diameter) of sample was placed into a centrifuge plastic tube and $1 \mathrm{~mL}$ of bacteria liquid was extracted and co-cultured for $2 \mathrm{~h}$. Then, the sample was removed and placed in the new BHI solution, then agitated for $10 \mathrm{~min}$. The $100 \mu \mathrm{L}$ was extracted and applied on the BHI Agar (Becton, Dickinson and Company, TX, USA) petri dish before being cultured for $17 \mathrm{~h}$ at $37^{\circ} \mathrm{C}$. Finally, the colonies were counted and the results were expressed as percentage reduction rates bacteria number $=$ $\left[\alpha \times 10^{11}\right]$, where $\alpha$ is the number of bacterial colonies.

\subsection{Statistical Analysis}

All data were expressed as mean \pm standard deviation (SD) from three repeat samples. The data were analyzed using JMP 13 software (Statistics Analysis System, NC, USA). A one-way ANOVA followed by a Tukey's HSD post hoc test was used to determine the level of significance, where $p<$ 0.05 was considered to be significant.

\section{Conclusions}

In this study, PVA-CoHA nanocomposite membranes show good swelling behavior, antibacterial, and bioactivity. At the same time, increasing the extensibility of the PVA reduces the damage caused by the dressing when pulled. It is expected that the release of cobalt ions in PVA-CoHA will reduce wound infection and reduce the damage caused by epithelial tissue attachment, discharge the bad tissue fluid through the excellent swelling effect, and keep the wound moist to promote healing. The results support our hypothesis that the addition of CoHA is very effective for the biological activity and anti-inflammatory properties of the membrane. Based on the above, the PVA-CoHA composite membrane described in this study can be a potential choice for diabetic traumas dressings. In the future, we will continue to explore the performance of the PVA-CoHA composite membrane on diabetic wound animal models.

Author Contributions: W.-C.L. is the core author for contributions to the analysis and interpretation of data, drafting of the manuscript, critical revision of the manuscript and carried out the experiment; C.-M.T. is the corresponding authors and contributed to the design and implementation of the research, to the analysis of the results, and to the writing of the manuscript. All authors have read and agreed to the published version of the manuscript.

Funding: This research was funded by the ministry of science and technology of Taiwan, Republic of China, via grants NSC-100-2221-E-040-001.

Conflicts of Interest: The authors declare no conflict of interest.

\section{References}

1. Young, M.; Boulton, A.; MacLeod, A.; Williams, D.; Sonksen, P. A multicentre study of the prevalence of diabetic peripheral neuropathy in the united kingdom hospital clinic population. Diabetologia 1993, 36, 150-154. [CrossRef] [PubMed]

2. Krasner, D.; Sibbald, R. Diabetic foot ulcer care: Assessment and management. In Levin and O'Neals The Diabetic Foot, 6th ed.; Mosby: St. Louis, MO, USA, 2001.

3. Foster, A.; Greenhill, M.; Edmonds, M. Comparing two dressings in the treatment of diabetic foot ulcers. J. Wound Care 1994, 3, 224-228. [CrossRef] [PubMed]

4. Boateng, J.S.; Matthews, K.H.; Stevens, H.N.; Eccleston, G.M. Wound healing dressings and drug delivery systems: A review. J. Pharm. Sci. 2008, 97, 2892-2923. [CrossRef] [PubMed]

5. Fonder, M.A.; Lazarus, G.S.; Cowan, D.A.; Aronson-Cook, B.; Kohli, A.R.; Mamelak, A.J. Treating the chronic wound: A practical approach to the care of nonhealing wounds and wound care dressings. J. Am. Acad. Dermatol. 2008, 58, 185-206. [CrossRef]

6. Tănase, E.E.; Popa, V.I.; Popa, M.E.; Râpă, M.; Popa, O. Biodegradation study of some food packaging biopolymers based on pva. Bull. Uasvm Anim. Sci. Biotechnol. 2016, 73, 1-5. [CrossRef] 
7. Baker, M.I.; Walsh, S.P.; Schwartz, Z.; Boyan, B.D. A review of polyvinyl alcohol and its uses in cartilage and orthopedic applications. J. Biomed. Mater. Res. Part B Appl. Biomater. 2012, 100, 1451-1457. [CrossRef]

8. Vijayasekaran, S.; Fitton, J.; Hicks, C.; Chirila, T.; Crawford, G.; Constable, I. Cell viability and inflammatory response in hydrogel sponges implanted in the rabbit cornea. Biomaterials 1998, 19, 2255-2267. [CrossRef]

9. Chen, W.; Hou, Y.; Tu, Z.; Gao, L.; Haag, R. Ph-degradable pva-based nanogels via photo-crosslinking of thermo-preinduced nanoaggregates for controlled drug delivery. J. Control. Release 2017, 259, 160-167. [CrossRef]

10. Ismail, H.; Freakley, P.; Sheng, E. The effect of carbon black particle size on multifunctional additive-carbon black interaction. Eur. Polym. J. 1995, 31, 1049-1056. [CrossRef]

11. Tang, C.-M.; Tian, Y.-H.; Hsu, S.-H. Poly(vinyl alcohol) nanocomposites reinforced with bamboo charcoal nanoparticles: Mineralization behavior and characterization. Materials 2015, 8, 4895-4911. [CrossRef]

12. Stojanović, Z.; Veselinović, L.; Marković, S.; Ignjatović, N.; Uskoković, D. Hydrothermal synthesis of nanosized pure and cobalt-exchanged hydroxyapatite. Mater. Manuf. Process. 2009, 24, 1096-1103. [CrossRef]

13. Veselinović, L.; Karanović, L.; Stojanović, Z.; Bračko, I.; Marković, S.; Ignjatović, N.; Uskoković, D. Crystal structure of cobalt-substituted calcium hydroxyapatite nanopowders prepared by hydrothermal processing. J. Appl. Crystallogr. 2010, 43, 320-327. [CrossRef]

14. Stanić, V.; Radosavljević-Mihajlović, A.S.; Živković-Radovanović, V.; Nastasijević, B.; Marinović-Cincović, M.; Marković, J.P.; Budimir, M.D. Synthesis, structural characterisation and antibacterial activity of ag+-doped fluorapatite nanomaterials prepared by neutralization method. Appl. Surf. Sci. 2015, 337, 72-80. [CrossRef]

15. Kramer, E.R.; Morey, A.M.; Staruch, M.; Suib, S.L.; Jain, M.; Budnick, J.I.; Wei, M. Synthesis and characterization of iron-substituted hydroxyapatite via a simple ion-exchange procedure. J. Mater. Sci. 2013, 48, 665-673. [CrossRef]

16. Fan, W.; Crawford, R.; Xiao, Y. Enhancing in vivo vascularized bone formation by cobalt chloride-treated bone marrow stromal cells in a tissue engineered periosteum model. Biomaterials 2010, 31, 3580-3589. [CrossRef] [PubMed]

17. Zhou, J.; Zhao, L. Hypoxia-mimicking co doped tio2 microporous coating on titanium with enhanced angiogenic and osteogenic activities. Acta Biomater. 2016, 43, 358-368. [CrossRef]

18. Kulanthaivel, S.; Mishra, U.; Agarwal, T.; Giri, S.; Pal, K.; Pramanik, K.; Banerjee, I. Improving the osteogenic and angiogenic properties of synthetic hydroxyapatite by dual doping of bivalent cobalt and magnesium ion. Ceram. Int. 2015, 41, 11323-11333. [CrossRef]

19. Tahmasebi Birgani, Z.; Fennema, E.; Gijbels, M.J.; de Boer, J.; van Blitterswijk, C.A.; Habibovic, P. Stimulatory effect of cobalt ions incorporated into calcium phosphate coatings on neovascularization in an in vivo intramuscular model in goats. Acta Biomater. 2016, 36, 267-276. [CrossRef]

20. Ignjatovic, N.; Ajdukovic, Z.; Rajkovic, J.; Najman, S.; Mihailovic, D.; Uskokovic, D. Enhanced osteogenesis of nanosized cobalt-substituted hydroxyapatite. J. Bionic Eng. 2015, 12, 604-612. [CrossRef]

21. Lin, W.-C.; Chuang, C.-C.; Wang, P.-T.; Tang, C.-M. A comparative study on the direct and pulsed current electrodeposition of cobalt-substituted hydroxyapatite for magnetic resonance imaging application. Materials 2019, 12, 116. [CrossRef]

22. Lin, W.C.; Yao, C.; Huang, T.Y.; Cheng, S.J.; Tang, C.M. Long-term in vitro degradation behavior and biocompatibility of polycaprolactone/cobalt-substituted hydroxyapatite composite for bone tissue engineering. Dent. Mater. 2019, 35, 751-762. [CrossRef] [PubMed]

23. Ionita, M.; Crica, L.E.; Tiainen, H.; Haugen, H.J.; Vasile, E.; Dinescu, S.; Costache, M.; Iovu, H. Gelatin-poly(vinyl alcohol) porous biocomposites reinforced with graphene oxide as biomaterials. J. Mater. Chem. B 2016, 4, 282-291. [CrossRef] [PubMed]

24. Vashisth, P.; Nikhil, K.; Roy, P.; Pruthi, P.A.; Singh, R.P.; Pruthi, V. A novel gellan-pva nanofibrous scaffold for skin tissue regeneration: Fabrication and characterization. Carbohydr. Polym. 2016, 136, 851-859. [CrossRef] [PubMed]

25. Bryaskova, R.; Pencheva, D.; Kale, G.M.; Lad, U.; Kantardjiev, T. Synthesis, characterisation and antibacterial activity of pva/teos/ag-np hybrid thin films. J. Colloid Interface Sci. 2010, 349, 77-85. [CrossRef]

26. Shi, Y.; Xiong, D.; Liu, Y.; Wang, N.; Zhao, X. Swelling, mechanical and friction properties of pva/pvp hydrogels after swelling in osmotic pressure solution. Mater. Sci. Eng. C Mater. Biol. Appl. 2016, 65, 172-180. [CrossRef] 
27. Mishra, S.K.; Ferreira, J.M.; Kannan, S. Mechanically stable antimicrobial chitosan-pva-silver nanocomposite coatings deposited on titanium implants. Carbohydr. Polym. 2015, 121, 37-48. [CrossRef]

28. Abdelrazek, E.M.; Elashmawi, I.S.; Labeeb, S. Chitosan filler effects on the experimental characterization, spectroscopic investigation and thermal studies of pva/pvp blend films. Phys. B Condens. Matter. 2010, 405, 2021-2027. [CrossRef]

29. Adhikari, B.B.; Kanemitsu, M.; Kawakita, H.; Ohto, K. Synthesis and application of a highly efficient polyvinylcalix [4] arene tetraacetic acid resin for adsorptive removal of lead from aqueous solutions. Chem. Eng. J. 2011, 172, 341-353. [CrossRef]

30. Nie, L.; Chen, D.; Suo, J.; Zou, P.; Feng, S.; Yang, Q.; Yang, S.; Ye, S. Physicochemical characterization and biocompatibility in vitro of biphasic calcium phosphate/polyvinyl alcohol scaffolds prepared by freeze-drying method for bone tissue engineering applications. Colloids Surf. B Biointerfaces 2012, 100, 169-176. [CrossRef]

31. Lim, Y.J.; Oshida, Y.; Andres, C.J.; Barco, M.T. Surface characterizations of variously treated titanium materials. Int. J. Oral Maxillofac. Implant. 2001, 16, 333-342.

32. Buser, D.; Broggini, N.; Wieland, M.; Schenk, R.K.; Denzer, A.J.; Cochran, D.L.; Hoffmann, B.; Lussi, A.; Steinemann, S.G. Enhanced bone apposition to a chemically modified sla titanium surface. J. Dent. Res. 2004, 83, 529-533. [CrossRef] [PubMed]

33. Saeed, A.M.; Hassan, R.A.; Thajeel, K.M. Synthesis of calcium hydroxyapatite powder from hen's eggshell. Iraqi J. Phys. 2011, 9, 24-28.

34. Lin, W.C.; Chuang, C.C.; Chang, C.J.; Chiu, Y.H.; Tang, C.M. The effect of electrode topography on the magnetic properties and mri application of electrochemically-deposited, synthesized, cobalt-substituted hydroxyapatite. Nanomaterials 2019, 9, 200. [CrossRef] [PubMed]

35. Kavitha, T.; Haider, S.; Kamal, T.; Ul-Islam, M. Thermal decomposition of metal complex precursor as route to the synthesis of co 3 o 4 nanoparticles: Antibacterial activity and mechanism. J. Alloy. Compd. 2017, 704, 296-302. [CrossRef]

Publisher's Note: MDPI stays neutral with regard to jurisdictional claims in published maps and institutional affiliations.

(C) 2020 by the authors. Licensee MDPI, Basel, Switzerland. This article is an open access article distributed under the terms and conditions of the Creative Commons Attribution (CC BY) license (http://creativecommons.org/licenses/by/4.0/). 